\title{
Reading Your PowerPoint Is Not Teaching
}

\author{
Deirdre Bonnycastle ${ }^{1}$
}

Published online: 26 October 2015

(C) International Association of Medical Science Educators 2015

Students, who aren't confronted with their misconceptions, leave the class thinking they know the content. Dr. Eric Mazur

I have been a teacher for 45 years, always with adults, and whether my students were street kids or medical doctors, the recurring question for me has always been "How do you know that people are learning what you hope to teach?" Early in my career, I thought that when they responded happily to my classes, it indicated that learning had occurred. Later, I began to realize that enjoyment and knowledge was not the same thing. In those early years of working with young adults, I learned that verbal inquiry between myself and my students led to a mutual knowledge sharing that was productive and powerful. I will never forget the young man who taught me, his teacher, how division of fractions could be illustrated using pizza.

Then, I moved to the university teaching environment and discovered a learned helplessness in both faculty and students that astounded me. For 700 years, universities have used the lecture transmission model. In 1300, when books were rare and expensive, knowledge had to be stored in teachers' heads and transmitted verbally to large groups of students. Students could not afford writing materials, so they listened closely and memorized what they were told. Those with good memories succeeded and passed what they learned onto the next generation.

Deirdre Bonnycastle

d.bonnycastle@usask.ca

1 University of Saskatchewan, Saskatoon, SK, Canada
Learned helplessness sets in when the world changes, but people just keep doing what they have always done because it is "the way it's supposed to be"; it is comfortable and feels right or change is scary. Study after study has demonstrated that lecturing is a poor learning model, especially in the sciences, but universities persist and students continue to expect a rousing lecture. I am a classic example since I frequently find myself changing from highly interactive sessions to lecture because it is easier and people like my lectures.

So here I am at IAMSE presenting a lecture on active learning to a very large group of scientists, and I have been wracking my brain for months trying to find ways to make the process interactive. Only in retrospect will you be telling me if I succeeded.

\section{My Definition of Engaged Learning}

Students are engaged in the learning process when their brains and/or bodies are interacting with the content. For example, I was recently teaching 20 first year medical students a class on the importance of observation. I gave them 15 minutes to walk around campus with a partner; no speaking was allowed during the walk. When they returned, they spent 10 minutes comparing notes with their partner about what they had seen. We then spent 30 minutes discussing as a group what they learned from the exercise. I could have given a lecture on perception, observation, and individual differences, but $20 \%$ of them would have been reading email, another $30 \%$ would have been thinking about other events in their lives, $25 \%$ would be frantically trying to take notes, and $25 \%$ would be listening intensely trying to remember what I said.

And that illustrates one method of interacting with student brains; engage them in storytelling. Why do you think storytelling has such a powerful impact? And that illustrates 
another method; ask a question that makes students think, even if it is rhetorical.
The illustration below reflects one concept of learning.

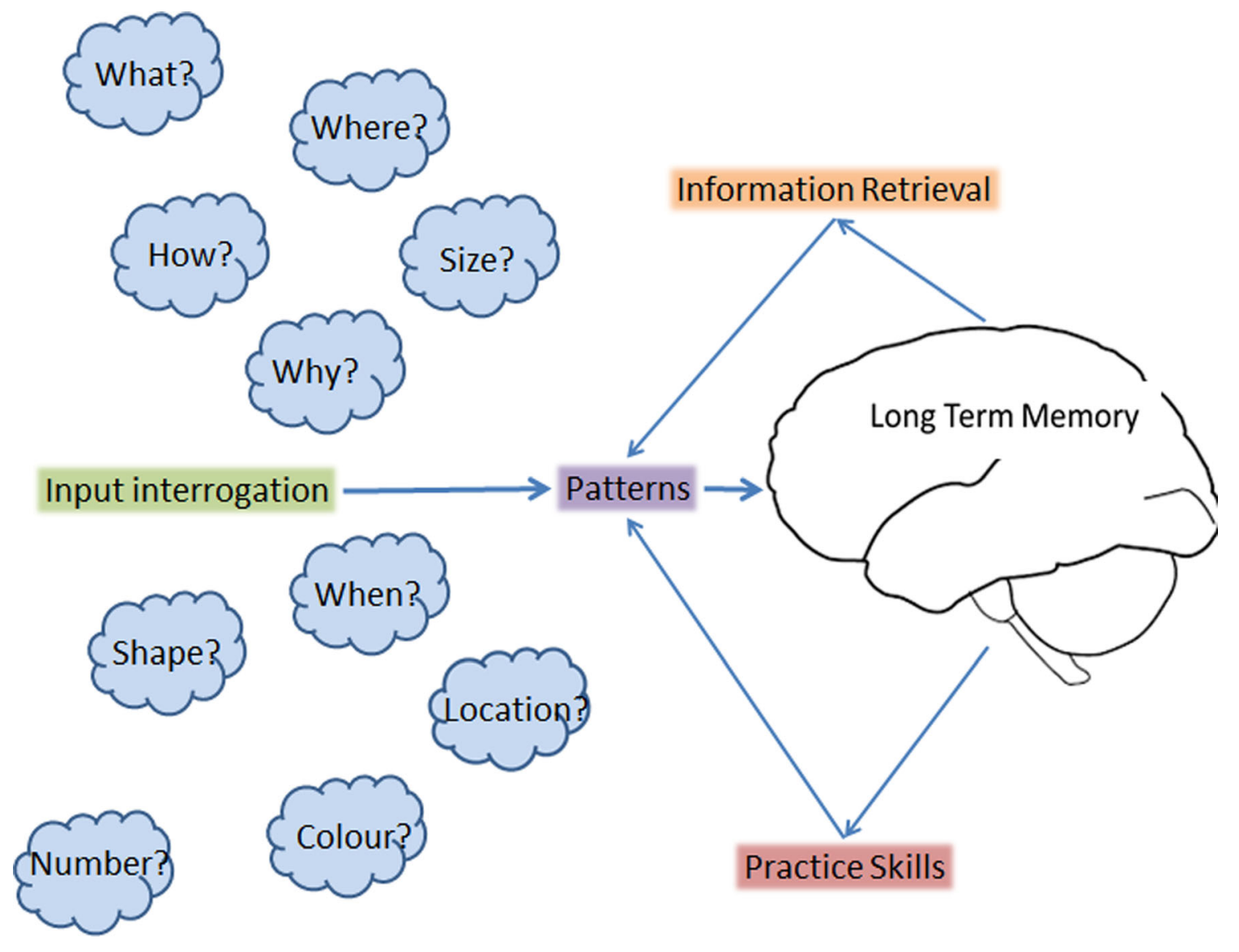

\section{How to Kick Start Your Class when Facebook Is Calling?}

First, you have got to get their attention! There are thousands of ways of doing this, but some of my favorites are:

1. Anonymous opinion polls (brain and body).

2. Patient stories to reflect relevance (brain).

3. Jigsaw puzzles - perfect in a flipped classroom. Small groups are given a topic to read up on in advance, then the groups are divided up to build concept maps of what they learned (brain and body).

4. Anonymous quizzes on the foundational knowledge required for class - if results are positive, ask why is $x$ the right answer; if 60-80 correct, ask them to pair up and discuss the answer and then retest. If less than $60 \%$, then reteach. Thank you Eric Mazur (brain and body).

\section{How Do You Confront Their Misconceptions?}

In spite of the title of this article, I am not anti-PowerPoint. PowerPoint saved my academic life because it gave me something to focus my attention on when professors were talking and putting me to sleep. Well done PowerPoint can be powerful; just remember that people cannot physically listen and read at the same time and they read faster than you speak.

I am a firm supporter of flipped classrooms and am very pleased that people here are presenting on that topic since I believe it is a more natural way of learning if done well.

Here are some ideas for engaging students in large classrooms:

1. Role model how you think through ideas in your discipline. Start by saying "the first question I would ask myself is ...." 
2. Walk them through the process of creating a concept map for this session. Concept maps help students learn patterns and increase their ability to remember in the long term.

3. Set up a role-play that illustrates a process you are trying to explain and have students physically act it out.

4. Use input interrogation tactics like asking open-ended questions in a way that invites curiosity not embarrassment; for example, "What do you need to learn about X?" or "How do you think this impacts on patient care?"

5. Quiz using "Write, pair, share."

6. Use games such as sorting into categories, crossword puzzles, or jeopardy to bring in healthy competition and improve retrieval.

7. Ask them during class "What questions need to be answered still?"

\section{How Do You Know that They Actually Learned Anything?}

Here you are at the end of class with all those faces watching you. Do not ask if they have any questions! Instead, try one of these:

1. If you were writing the exam tomorrow, what questions would you expect on this topic?

2. Ask them to list the key points for today. A tool like Yawnbusters can help you create an electronic version instead of a flipchart version. Ask one of your students to record the answers while you encourage responses.

3. Redo an anonymous opinion poll to see if the answers have changed.

4. Encourage classroom curation with tools like Diigo where students can share resources they found.

5. Anonymous quiz, but only if you did not do one already. Quizzes like this are a method of retrieval, which helps long-term memory.

\section{Go Forth and Engage}

As a teacher, some of these techniques will feel awkward and clumsy; this is a normal part of learning something new. Pick one or two things to start the process and add to your repertoire as you become more comfortable.

Your students may also feel awkward and reluctant because they spend 30 years learning to excel with outdated technology. Accept that and help with the transition.

\section{Resources}

More active learning ideas: http://medicaleducation. wikifoundry.com/page/Active\%20Engagement

My flipped classroom pages: http://medicaleducation. wikifoundry.com/page/Flipped\%20Classroom and http:// medicaleducation.wikifoundry.com/page/Using + the + Flipped+Classroom+Group+Time

Eric Mazur: http://mazur.harvard.edu/emdetails.php

Veritasium science-teaching videos including an overview of learned helplessness: https://www.youtube.com/user/ 1 veritasium

Collaborative Mindmapping: http://c4lpt.co.uk/directoryof-learning-performance-tools/collaborative-mindmappingtools/

Collaborative Whiteboards: http://c4lpt.co.uk/directory-oflearning-performance-tools/collaborative-whiteboards/

\section{Tools Used in My Presentation}

MindMeister Collaborative Mindmap: https://www. mindmeister.com/

Mentimeter: https://www.mentimeter.com/

AnswerGarden: http://answergarden.ch/

Yawnbuster Interactive PowerPoint: http://www. yawnbuster.com/

\section{Note of the Editor-in-Chief}

Since the IAMSE meeting, the IAMSE manual "How-to guide for Active Learning" has been published. For more information see the IAMSE website. 